\title{
iTRAQ-based quantitative proteome analysis reveals metabolic changes between a cleistogamous wheat mutant and its wild-type wheat
}

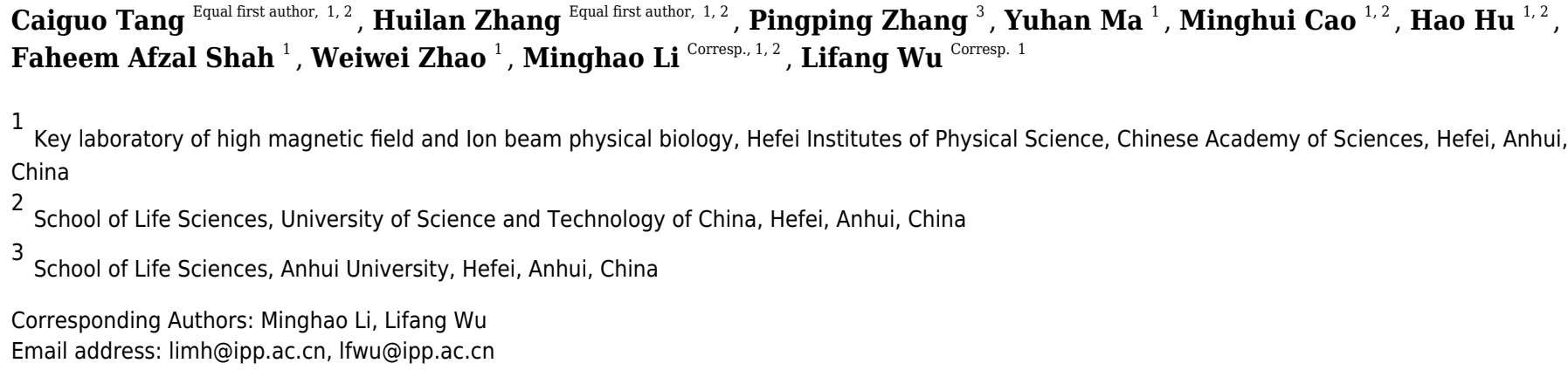

Background: Wheat is one of the most important staple crops worldwide. Fusarium head blight severely affects wheat yield and quality. A novel bread wheat mutant, ZK001, characterised as cleistogamic was isolated from a non-cleistogamous variety (YM18) through static magnetic field mutagenesis. Cleistogamy is a promising strategy for controlling Fusarium head blight. However, little is known about the mechanism of cleistogamy in wheat. Methods: We performed a Fusarium head blight resistance test to identify the Fusarium head blight infection rate of ZK001. We also measured the agronomic traits of ZKOOI and the starch and total soluble sugar contents of lodicules in YM18 and ZK001. Finally, we performed comparative studies at the proteome level between YM18 and ZKO01 based on the proteomic technique of isobaric tags for relative and absolute quantification. Results: The infection rate of ZKOOI was lower than that of its wild type and AK58. The abnormal lodicules of ZKO01 lost the ability to push the lemma and palea apart during the flowering stage. Proteome analysis showed that the main differentially abundant proteins were related to carbohydrate metabolism, protein transport, and calcium ion binding. These differentially abundant proteins may work together to regulate cellular homeostasis, osmotic pressure and the development of lodicules. This hypothesis is supported by the analysis of starch, soluble sugar content in the lodicules as well as the results of qRT-PCR. Conclusions: Proteomic analysis has provided comprehensive information that should be useful for further research on the lodicule development mechanism in wheat. The ZKOO1 mutant is optimal for studying flower development in wheat and could be very important for Fusarium head blight resistant projects via conventional crossing. 


\section{ITRAQ-based quantitative proteome analysis reveals}

2 metabolic changes between a cleistogamous wheat

3 mutant and its wild-type wheat

4

5

6

7

8

Caiguo Tang ${ }^{1,2, \dagger}$, Huilan Zhang ${ }^{1,2, \dagger}$, Pingping Zhang ${ }^{3}$, Yuhan $\mathrm{Ma}^{1}$, Minghui Cao ${ }^{1,2}$, $\mathrm{Hao} \mathrm{Hu}{ }^{1,2}$, Faheem Afzal Shah ${ }^{1}$, Weiwei Zhao ${ }^{1}$, Minghao Li ${ }^{1,2, *}$ and Lifang $\mathrm{Wu}^{1, *}$

${ }^{1}$ Key laboratory of high magnetic field and Ion beam physical biology, Hefei Institutes of Physical Science, Chinese Academy of Sciences, Hefei, Anhui, China;

${ }^{2}$ School of Life Sciences, University of Science and Technology of China, Hefei, Anhui, China

${ }^{3}$ School of Life Sciences, Anhui University, Hefei, Anhui, China

$\dagger$ These authors contributed equally to this work.

*Corresponding Author:

Minghao Li; Lifang Wu

350 Shushanhu Road, Hefei 230031, Anhui, P. R. China

Email address: limh@ipp.ac.cn (M.L); 1fwu@ipp.ac.cn (L.W)

\section{Abstract}

Background: Wheat is one of the most important staple crops worldwide. Fusarium head blight severely affects wheat yield and quality. A novel bread wheat mutant, ZK001, characterised as cleistogamic was isolated from a non-cleistogamous variety (YM18) through static magnetic field mutagenesis. Cleistogamy is a promising strategy for controlling Fusarium head blight. However, little is known about the mechanism of cleistogamy in wheat.

Methods: We performed a Fusarium head blight resistance test to identify the Fusarium head blight infection rate of $Z K 001$. We also measured the agronomic traits of ZKO01 and the starch and total soluble sugar contents of lodicules in YM18 and ZK001. Finally, we performed comparative studies at the proteome level between YM18 and ZK001 based on the proteomic technique of isobaric tags for relative and absolute quantification.

Results: The infection rate of ZK001 was lower than that of its wild type and AK58. The abnormal lodicules of ZKO01 lost the ability to push the lemma and palea apart during the flowering stage. Proteome analysis showed that the main differentially abundant proteins were related to carbohydrate metabolism, protein transport, and calcium ion binding. These differentially abundant proteins may work together to regulate cellular homeostasis, osmotic pressure and the development of lodicules. This hypothesis is supported by the analysis of starch, soluble sugar content in the lodicules as well as the results of qRT-PCR. 
39 Conclusions: Proteomic analysis has provided comprehensive information that should be useful 40 for further research on the lodicule development mechanism in wheat. The ZK001 mutant is 41 optimal for studying flower development in wheat and could be very important for Fusarium head 42 blight resistant projects via conventional crossing.

43

\section{Introduction}

45 Bread wheat (Triticum aestivum L.) is one of the most important staple crops worldwide. The 46 world population continues to grow and arable area is decreasing year by year, therefore higher production in crop plants may prove to be necessary to satisfy the increasing demand for food (FAO, 2015). However, many challenges, inclding biotic and abiotic stresses, severely affect wheat fields and product quality. For instance, Fusarium head blight (FHB) is critically damaging wheat security (Walter, Nicholson \& Doohan, 2010), and the application of chemical insecticides and fungicides is increasing the amounts of residues in wheat and in the environment (Hollingsworth et al., 2008). Therefore, scientists and breeders have to find eco-friendly and costeffective strategies to guarantee wheat yield and quality..

In the last decade, severe epidemics caused by Fusarium spp. have occurred worldwide with up to $100 \%$ yield loss recorded under optimal disease conditions (Yumurtaci et al., 2017). The pore-forming toxin-like (PFT) gene at the quantitative trait locus (QTL) Fhbl, which was the first FHB-resistance gene isolated, was found to confer resistance to FHB in Sumai 3 (SM3) (Rawat et al., 2016). FHB infection usually occurs on the inner surfaces of lemmas and paleae after 59 germination of the Fusarium spp. conidia (Zange, Kang \& Buchenauer, 2005). The anther can provide the initial path for FHB infection (Pugh, Johann \& Dickson, 1933; Walter, Nicholson \& Doohan, 2010); therefore, cleistogamous cultivars, which contain few anthers exposed to glumes, may provide structural barriers for diseases that appear during the flowering stage. In barley (Hordeum vulgare L.), cleistogamous cultivars, which self-fertilize within permanently closed flowers (Culley \& Klooster, 2007), showed greater resistance to FHB infection than chasmogamous cultivars, which have open flowers (Yoshida, Kawada \& Tohnooka, 2005). In wheat, cleistogamous cultivars such as U24 have a lower risk of FHB infection than chasmogamous cultivars such as Saikai 165 (Kubo et al., 2010). Therefore, cleistogamy might be the basis for new strategies for controlling Fusarium head blight in cereal crops.

Cleistogamy in barley is genetically determined by the presence of the recessive allele clyl, 70

71

72

73

74

75

76

77

78 but the dominant allele at the linked locus, $C l y 2$, is epistatic over $c l y 1$ (Wang et al., 2013). Loss of the miRNA172 target site causes $c l y 1$ to express a protein, $H v A P 2$, which effectively suppresses lodicule swelling (Turuspekov et al., 2004; Nair et al., 2010; Wang et al., 2015). In rice (Oryza sativa L.), there are many cleistogamous mutants resulting from abnormal lodicules. A single recessive gene, lodiculeless spikelet $(t)[l d(t)]$, controls the cleistogamous mutant lacking lodicules (Won \& Koh, 1998; Maeng et al., 2006). Another rice mutant, which has a truncated DEP2 determined by the $c l 7(t)$ gene, has a cleistogamous phenotype because of weak swelling ability in the lodicules (Ni et al., 2014). A third rice mutant, spwl-cls, has normal stamens, but the lodicules are transformed homeotically into lodicule-glume mosaic organs, thereby engendering 
cleistogamy with temperature-sensitivity (Yoshida et al., 2007; Ohmori et al., 2012). A novel temperature-stable cleistogamous mutant, $s p w 1-c l s 2$, can maintain the cleistogamous phenotype under low temperatures (Lombardo et al., 2017). The glumes open in the flowering stage because the swelling of the lodicule is primarily responsible for pushing the lemma and palea, thereby opening the floret (Nair et al., 2010). In contrast, there is very little information on cleistogamy in wheat.

The probability of primary infection is approximately proportional to the number of spores reaching the open florets during the flowering process; accordingly, the breeding of varieties with flowers that are partially or completely cleistogamous might reduce Fusarium susceptibility in wheat (Schuster \& Ellner, 2008). In order to probe the mechanism of cleistogamy, Ning et al. ( 2013) studied the structure, transcription and post-transcriptional regulation of the cleistogamous gene $T a A P 2$, which is homologous in barley and wheat. TaAP2 alleles may also generate a cleistogamous wheat and improve resistance to FHB. Additionally, anther extrusion is a complex trait with significant markers; it has either favourable or unfavorable additive effects and imparts minor to moderate levels of phenotypic variance in spring and winter wheat (Muqaddasi et al., 2017).

Large-scale transcriptomic analyses have been employed in wheat to better understand the molecular mechanisms of flower development (Winfield et al., 2010; Diallo et al., 2014; Feng et al., 2015; Kumar et al., 2015; Yang et al., 2015; Ma et al., 2017). However, because of posttranscriptional and post-translational modifications, mRNA levels do not always correlate with the corresponding protein levels (Schweppe et al., 2003; Canovas et al., 2004; Zhao et al., 2013). Proteins are directly correlated with cellular functions (Yan et al., 2005; Zhang et al., 2012); therefore, proteomic analysis is essential for studying global protein expression levels in wheat to further unravel the complex mechanisms of cleistogamy. In particular, isobaric tags for relative and absolute quantitation (iTRAQ) technology, which is a quantitative gel-free proteomic approach, coupled with liquid chromatography-tandem mass spectrometry (LC-MS/MS) enables the direct quantification and comparison of protein levels among samples with more efficiency and accuracy than traditional gel-based techniques which fail to identify low-abundance protein species and have limitations for identifying proteins with extreme biochemical properties (Wu et al., 2006).

Here, we show that an SMFs-induced wheat mutant, ZK001, is a cleistogamous line with lower FHB infection vulnerability than the chasmogamous line Yumai 18 (YM18). Additionally, we performed a comparative proteomic analysis of different development stages in YM18 and ZK001 to characterise the protein expression profiles. In this manner, we aimed to provide insight into proteomic changes associated with the cleistogamous phenotype in wheat, specifically exploring lodicule expanding mechanisms at the protein level. Our results have the potential to benefit future research efforts in controlling FHB via conventional breeding, advance the study of wheat flower development, and contribute to better control of genetically modified lines of agriculturally important crops; this could lead to time and cost-savings in the effort to refine genotypes. 


\section{Materials \& Methods}

\section{Plant Material}

121 The cleistogamy mutant line $Z K 001$, was isolated from a mutagenised population of wheat variety

122 YM18, using an SMFs of 7 Tesla for 5 hours. After mutagenesis, it propagated via self-pollination

123 until the cleistogamous phenotype was completely stable. All wheat seeds were stored at the Hefei

124 Institutes of Physical Science, Chinese Academy of Sciences (CASHIPS), Anhui, P. R. China.

125 SM3, Aikang 58 (AK58), YM18 and ZK001 were grown in a greenhouse in an experimental field

$126\left(31^{\circ} 54^{\prime} \mathrm{N}, 117^{\circ} 10^{\prime} \mathrm{E}\right)$ at CASHIPS. AK58 and YM18, which are both varieties in the northern

127 China, were not resistant to FHB infection (Yu et al., 2019). Therefore, AK58 was used as

128 susceptible control. Fertilizer and weed management were similar to methods used in the process

129 for wheat breeding (Li et al., 2014). The spikelets and lodicules of YM18 and ZK001, which had

130 three biological replicates, were harvested during the white anther stage (WAS), green anther stage

131 (GAS), yellow anther stage (YAS), and anthesis stage (AS) (Zadoks, Chang \& Konzak, 1974;

132 Kirby \& Appleyard, 1987; Guo \& Schnurbusch, 2015). These samples were collected and frozen

133 in liquid nitrogen and preserved at $-80^{\circ} \mathrm{C}$.

134 Starch and total soluble sugar content

135 Twenty pairs of lodicules with three biological replications from YM18 and ZK001 were sampled

136 and snap frozen in liquid nitrogen at the four flower development stages. The samples were ground

137 using Tissuelyser-24 (Shanghai Jingxin Industrial Development Co., Ltd.) for 45 seconds at 50

$138 \mathrm{~Hz}$.

139 Starch and total soluble sugars were extracted following the instructions included with the Starch

140 Content and Plant Soluble Sugar Content test kits (Nanjing Jiancheng Bioengineering Institute).

141 The starch and total soluble sugars in the supernatant were determined using a UV-VIS

142 spectrophotometer (Lambda 365, PerkinElmer) with a wavelength of $620 \mathrm{~nm}$. The starch and total

143 soluble sugar contents were calculated using the following formulas:

144

145

$$
C_{\text {starch }}=\frac{O D_{\text {sample }}-O D_{\text {blank }}}{O D_{\text {standard }}-O D_{\text {blank }}} \times \frac{C_{\text {standard } 1} \times V_{\text {pretreatment }} \times \text { Dilution ratio }}{\mathrm{N}_{\text {total PL }}}
$$

$$
C_{\text {total souble sugar }}=\frac{\mathrm{OD}_{\text {sample }}-\mathrm{OD}_{\text {blank }}}{O \mathrm{D}_{\text {standard }}-\mathrm{OD}_{\text {blank }}} \times \frac{\mathrm{C}_{\text {standard } 2} \times \text { Dilution ratio }}{10 \times \mathrm{V}_{\text {distilled water }} \times \mathrm{N}_{\text {total PL }}}
$$

Note: PL: pair of lodicules, $\mathrm{C}_{\text {starch}}$ : the starch content in lodicule $\left(\mu \mathrm{g} \cdot \mathrm{PL}^{-1}\right), \mathrm{C}_{\text {total souble sugar }}$ : the total souble sugar content in lodicule $\left(\mu \mathrm{g} \cdot \mathrm{PL}^{-1}\right), \mathrm{C}_{\text {standard } 1}$ : standard solution 1 concentration $=200$ $\mu \mathrm{g} \cdot \mathrm{mL}^{-1}, \mathrm{C}_{\text {standard } 2}$ : standard solution 2 concentration $=100 \mu \mathrm{g} \cdot \mathrm{mL}^{-1}$, Dilution ratio $=1, \mathrm{~V}_{\text {pretreatment }}$ : 
152 the volume of pretreatment solution $=1.7 \mathrm{~mL}, \mathrm{~V}_{\text {distilled water }}$ : the volume of distilled water used for 153 homogenising $=1 \mathrm{~mL}, \mathrm{~N}_{\text {total PL }}$ : the total number of PL which were sampled $=20$.

154

155

156

157

158

159

160

161

162

163

164

165

166

167

168

169

170

171

172

173

174

175

176

177

178

179

180

181

182

183

184

185

186

187

188

189

190

191

\section{Observation of spikes and lodicules}

Spike images of YM18 and ZK001 were photographed (D90, Nikon) at the AS. After 90 minutes, the lodicules of YM18 and ZK001, which were separated from the central young spikes in triplicate during GAS and cultured on Murashige and Skoog (MS) medium, were observed with an upright fluorescence stereomicroscope (SZX10, Olympus) and photographed (DP72, Olympus).

\section{FHB resistance testing}

FHB resistance testing was performed during the flowering stage of SM3, AK58, YM18 and ZK001 in the greenhouse by spraying the FHB spore F0601 (Fusarium graminearum Schw. cv. F0601) in both 2013-2014 and 2014-2015. The inoculum (50 $\mu \mathrm{L}$ at 105 spores per $\mathrm{mL}$ ) was deposited by spraying both sides of the ears. The diseased spikelet rate was calculated using the following formula:

Diseased spikelets rate $=\frac{\mathrm{N}_{\text {infected spikelets }}}{\mathrm{N}_{\text {total spikelets }}} \times 100 \%$.

Note: $\mathrm{N}_{\text {infected spikelets: }}$ the number of infected spikelets, $\mathrm{N}_{\text {total spikelets: }}$ the number of total spikelets.

\section{Protein extraction and iTRAQ labelling}

Total soluble proteins were extracted according to a published procedure (Yang et al., 2013) with slight modifications. Briefly, moderate amounts of the samples were separately frozen using liquid $\mathrm{N}_{2}$ and ground in $-20^{\circ} \mathrm{C}$ pre-cooled pestles and mortars with urea extraction buffer containing 150 $\mathrm{mM}$ Tris-HCl ( $\mathrm{pH}$ 7.6), $8 \mathrm{M}$ urea, 0.5\% SDS, 1.2\% Triton X-100, 20 mM EDTA, 20 mM EGTA, $50 \mathrm{mM} \mathrm{NaF}, 1 \%$ glycerol 2-phosphate, $5 \mathrm{mM}$ DTT, and $0.5 \%$ phosphatase inhibitor mixture 2 (Sigma). The mixtures were centrifuged at $10,000 \times \mathrm{g}$ for $1 \mathrm{~h}$ at $4{ }^{\circ} \mathrm{C}$, then the supernatants were mixed with pre-cooled acetone/methanol and incubated for $1 \mathrm{~h}$ at $-20{ }^{\circ} \mathrm{C}$. The mixtures were centrifuged at $15,000 \times \mathrm{g}$ for $15 \mathrm{~min}$ at $4{ }^{\circ} \mathrm{C}$. The pellets were washed twice with cold acetone. Pellets were dried and solubilised in lysis buffer containing $50 \mathrm{mM}$ Tris- $\mathrm{HCl}(\mathrm{pH} 6.8), 8 \mathrm{M}$ urea, $5 \mathrm{mM}$ DTT, $1 \%$ SDS, and $10 \mathrm{mM}$ EDTA. Protein concentrations of the samples were estimated using the Bradford method (Bradford, 1976) (Table S1) and the samples were stored at $-80{ }^{\circ} \mathrm{C}$ for further use. All protein samples were checked via sodium dodecyl sulfate polyacrylamide gel electrophoresis (SDS-PAGE) according to the Schägger protocol (Schägger, 2006). SDS-PAGE gels (Figure S1) were stained with Coomassie Brilliant Blue (CBB) staining solution (Coomassie Blue Fast Staining Solution, Beijing Dingguo Changsheng Biotechnology Co., LTD) (Kang et al., 2002).

After determining the protein concentration, we digested the samples with trypsin (Promega, V5113) and then incubated them for $12-16 \mathrm{~h}$ at $37^{\circ} \mathrm{C}$. Approximately $100 \mu \mathrm{g}$ of peptides of the different samples were labelled with iTRAQ based on the protocol of Unwin et al. (Unwin, Griffiths \& Whetton, 2010). The peptides of the different samples were labelled with iTRAQ 
192 reagents (isobaric tags 113, 114, 115, 116, 117, 118, 119, and 121 for groups YM18-WAS, ZK001193 WAS, YM18-GAS, ZK001-GAS, YM18-YAS, ZK001-YAS, YM18-AS, and ZK001-AS, 194 respectively) according to the manufacturer's instructions (Applied Biosystems).

195

196

197

198

199

200

201

202

203

204

205

206

207

208

209

210

211

212

213

214

215

216

217

218

219

220

221

222

223

224

225

226

227

228

229

230

231

\section{HPLC grading of $\mathrm{C}_{18}$ columns at high $\mathrm{pH}$ and LC-electrospray ionization-MS/MS analysis}

The lyophilised peptide mixture was reconstituted with $100 \mu \mathrm{L}$ of solution A ( $2 \%$ acetonitrile $(\mathrm{ACN})$ and $20 \mathrm{mM}$ ammonium formate, $\mathrm{pH} 10$ ). Then, the samples were loaded onto a reversephase column [ $\mathrm{C}_{18}$ column, $1.9 \mu \mathrm{m}$ (particle size), $150 \mu \mathrm{m}$ (inner diameter) $\times 120 \mathrm{~mm}$ (length), Waters] and eluted using a step linear elution program (Table S2). The samples were collected every $1.5 \mathrm{~min}$ and centrifuged at $14,000 \times \mathrm{g}$ for $5-90 \mathrm{~min}$. The 60 collected fractions were dried and re-dissolved with $5 \mu \mathrm{L} 0.5 \%$ formic acid (FA). The collected fractions were finally combined into 10 pools and centrifuged at $14,000 \times \mathrm{g}$ for $10 \mathrm{~min}$.

The reconstituted peptides were analysed with a Q-Exactive HF mass spectrometer (Thermo Fisher Scientific) coupled with a nano high-performance liquid chromatography system (1260 Infinity II, Agilent) (Scheltema et al., 2014). The peptides were loaded onto a $\mathrm{C}_{18}$ reversed-phase column $\left[\mathrm{C}_{18}\right.$ column, $3 \mu \mathrm{m}$ (particle size), $100 \mu \mathrm{m}$ (inner diameter) $\times 200 \mathrm{~mm}$ (length), Thermo Scientific] using mobile phases $\mathrm{A}\left(0.1 \% \mathrm{FA} / \mathrm{H}_{2} \mathrm{O}\right)$ and $\mathrm{B}(0.08 \% \mathrm{FA}, 80 \% \mathrm{ACN})$ (Table S3). The HPLC effluent was directly electrosprayed into the mass spectrometer and analysed based on preset parameters (Figure S2).

\section{Data analysis}

The raw mass data were processed for peptide identification using Proteome Discoverer 1.4 (ver. 1.4.0.288, Thermo Fisher Scientific) with specific parameters (Table S4) for searching the UniProt Triticum database. A false discovery rate (FDR) of $\leq 0.01$ was estimated for protein identification using a target-decoy search strategy (Elias \& Gygi, 2007). The mass spectrometry proteomics data have been deposited in the ProteomeXchange Consortium (http://proteomecentral.proteomexchange.org) via the PRIDE partner repository (Vizcaino et al., 2016 ) with the dataset identifier $<$ PXD010188 $>$. Increasing and decreasing abundant proteins were determined based on 1.5-fold-changes and peptides spectral matches (PSMs) $\geq 2$ (Sharma et al., 2017) between ZK001-WAS and YM18-WAS (Group 1), ZK001-GAS and YM18-GAS (Group 2), ZK001-YAS and YM18-YAS (Group 3), ZK001-AS and YM18-AS (Group 4), YM18WAS and YM18-GAS (Group 5), YM18-WAS and YM18-YAS (Group 6), YM18-WAS and YM18-AS (Group 7), ZK001-WAS and ZK001-GAS (Group 8), ZK001-WAS and ZK001-YAS (Group 9), and ZK001-WAS and ZK001-AS (Group 10).

Protein annotation was conducted by a BLAST search against NCBI and UniProt databases. Protein function was classified based on the following databases: Gene Ontology (http://www.geneontology.org/, GO), and Kyoto Encyclopedia of Genes and Genomes (http://www.genome.jp/kegg/, KEGG). For analysis of differentially abundant proteins (DAPs), significant GO enrichment and KEGG enrichment were defined as a corrected FDR with a $P-$ value less than 0.01 (Benjamini \& Hochberg, 1995). Proteins containing at least two peptide spectral matches (PSMs) per protein and fold change ratios $\geq 1.5$ or $\leq 0.67$ were considered more abundant or less abundant proteins, respectively. In order to validate the DAPs profile, we searched 
232 the EnsemblPlants database (http://plants.ensembl.org/index.html) for corresponding DNA 233 sequences. A total of 10 DAPs involved in carbohydrate metabolism and calcium ion binding and 234 transport were selected for qRT-PCR validation.

\section{Quantitative real-time PCR validation}

236 Total RNA was isolated using a Plant RNA kit (Omega, R6827) according to the manufacturer's 237 instructions. The quality of each RNA sample was checked on 1\% agarose gels. Measurement of 238 the concentration of RNA samples was performed using a NanoDrop 2000 spectrophotometer 239 bioanalyzer (Thermo Fisher Scientific). cDNAs were synthesised using TransScript One-Step 240 gDNA Removal and cDNA Synthesis SuperMix (Transgen Biotech) according to the 241 manufacturer's protocol. qRT-PCR was used to measure the transcript levels of the proteins of 242 interest. Each experiment was performed in three technical replicates with three biological 243 replicates. Target gene-specific primers (Table S5) were designed using the online software Primer 2443 version 0.4 .0 (http://bioinfo.ut.ee/primer3-0.4.0/primer3/) (Untergasser et al., 2012). 245 Quantitative reverse transcription polymerase chain reaction (qRT-PCR) was performed according 246 to the manufacturer's instructions for the FastStart Essential DNA Green Master (Roche), run on 247 the Roche LightCycler ${ }^{\circledR} 96$ Instrument. The glyceraldehyde-3-phosphate dehydrogenase gene 248 from $T$. aestivum ( $T a G A P D H$, GI: 7579063) served as an internal control and the relative 249 expression of target genes was calculated using the $2^{-\Delta \Delta \mathrm{CT}}$ method (Livak \& Schmittgen, 2001).

250 Statistical data analysis

251 The experimental data values represented the average of the measurements conducted from three 252 independent assays and were expressed as the mean \pm standard error of the mean (SEM). The data 253 were further analysed using ANOVA followed by Duncan's test (SPSS 18.0, IBM, Somers, NY, 254 USA). The level of significance was set at $P \leq 0.05$.

\section{Results}

256

257

258

259

260

261

262

263

264

265

266

267

268

269

270

271

\section{Comparative resistance to Fusarium head blight}

The results of FHB resistance testing showed that the infection rate in Sumai 3 (SM3) and ZK001 were $7.03 \%$ and $9.39 \%$ in $2013-2014$ and $8.61 \%$ and $17.60 \%$ in $2014-2015$, respectively (Table 1). Compared to SM3 and ZK001, YM18 and Aikang (AK58) were highly susceptible: the FHB infection rate was $35.16 \%$ and $38.12 \%$ in $2014-2015$, respectively. However, the diseased spikelet rates for YM18 and AK58 were $15.20 \%$ and $20.41 \%$ in 2013-2014, respectively, which was half the rate in 2014-2015 (Table 1). This indicates that the FHB infection rate is greatly influenced by environmental factors. These results suggest that cleistogamous cultivars have a lower FHB infection rate than chasmogamous cultivars.

\section{Comparison of flowering in YM18 and ZK001}

In accordance with previous reports, the exserted anthers increased the incidence of FHB (Sage \& De Isturiz, 1974; PARRY, JENKINSON \& McLEOD, 1995). Furthermore, the anthers of cleistogamy wheat were detained in glums during the flowering stage. Although the individual lines of YM18 and ZK001 were grown under the same growth and environmental conditions, the morphological differences were obvious. In YM18, the anthers extruded from the palea and lemma at the AS, whereas no anthers were observed in ZK001 at all flower development stages (Figure 
272 1A). The morphology of the lodicules of YM18 and ZK001 was also obviously different. In order 273 to investigate their morphology, we harvested the lodicules of YM18 and ZK001 at the GAS and 274 cultured them for 90 minutes on MS medium. The width of the YM18 lodicules (Figure 1B) was 275 greater than that of the ZK001 lodicules (Figure 1C and 1D).

276 Physiological characteristics of lodicules in YM18 and ZK001

277 To reveal the cause of the lodicules difference between YM18 and ZK001, we measured the starch 278 and total soluble sugar contents in the lodicules of YM18 and ZK001 at the four flower 279 development stages. Lodicule starch (Figure 2A, Table S6) and total soluble sugar (Figure 2B, 280 Table S6) contents showed an overall increase from the WAS to the AS for YM18 and ZK001. No 281 significant differences in the starch and soluble sugar contents in the lodicule were observed 282 between YM18 and ZK001 during the WAS or GAS. Additionally, the starch and total soluble 283 sugar contents in $Z K 001$ during the YAS significantly decreased 2.40 and 1.75-fold, respectively 284 (both $P<0.05$ ), compared with those in YM18, detected in one pair of lodicules (Figure 2, Table 285 S6). In contrast, the starch and total soluble sugar contents in ZK001 during the AS remarkably 286 287 288 289 290

291

292

293

294

295

296

297

298

299

300

301

302

303

304

305

306

307

308

309

310

311 increased 3.57 and 1.52-fold, respectively (both $P<0.05$ ), compared with those in YM18, detected in one pair of lodicules (Figure 2, Table S6).

\section{Overview of quantitative proteome analysis}

In order to study the protein expression patterns in YM18 and ZK001, we examined and quantitatively catalogued the proteomes of YM18 and ZK001 in the four flower development stages using iTRAQ technology. In this study, 19,422 peptides were matched to 4,497 proteins in the samples (Table S7); in addition, 11,603 unique peptides were found, and 2,172 proteins were identified with more than two unique peptide sequences excluding post-translational modifications. As shown in Figure 3A, more than $99 \%$ of the peptides covered proteins within the 36 peptides, and protein quantity decreased as the number of matching peptides increased. In terms of protein mass distribution, good coverage (an average of $10 \%-18 \%$ of total proteins in each protein-mass group) was obtained for proteins $>10 \mathrm{kDa}$ and $<60 \mathrm{kDa}$ (Figure 3B). The length of the identified peptides was between 10 and 13 amino acids at the peak and approximately $93 \%$ of the peptide length was within 24 amino acids (Figure 3C). Over $77 \%$ of the proteins had $>5 \%$ sequence coverage. Additionally, sequence coverage distribution was high in most of the identified proteins: More than $58 \%$ had over $>10 \%$ coverage and more than $37 \%$ had over $20 \%$ coverage (Figure 3D). These results indicate that the identified peptides were sufficient for protein identification.

\section{Cluster analysis of protein expression at four developmental stages}

In order to identify more differentially abundant proteins (DAPs), we compared DAPs in YM18 and ZK001 in the flowering development process, ZK001-WAS vs YM18-WAS (Group 1), ZK001-GAS vs YM18-GAS (Group 2), ZK001-YAS vs YM18-YAS (Group 3), ZK001-AS vs YM18-AS (Group 4), YM18-WAS vs YM18-GAS (Group 5), YM18-WAS vs YM18-YAS (Group 6), YM18-WAS vs YM18-AS (Group 7), ZK001-WAS vs ZK001-GAS (Group 8), ZK001WAS vs ZK001-YAS (Group 9), and ZK001-WAS vs ZK001-AS (Group 10). Increasing abundance and decreasing abundance proteins were determined based on fold-changes (FC) of $>$ 
3121.5 or $<0.667$ for expression difference comparison. For further screening, approximately 16,47 , $3132,0,11,124,105,15,298$ and 188 DAPs were identified with a corrected $P$-value for GO KEGG 314 enrichment less than 0.01 in groups 1 to 10 (Table 2). A Venn diagram of the DAPs and their 315 overlap in Group 1 and Group 2 showed that two common DAPs were increased-abundance and 3161 common DAP was decreased-abundance (Figure S3). Group 3 and Group 4 showed no overlap 317 with Group 1 or Group 2 (Figure S3). Venn diagrams indicated that 6, 10, 32, 206, 57, and 140 318 DAPs were specific DAPs of Groups 5, 8, 6, 9, 7, and 10, respectively (Figure S3).

319 Functional classification and subcellular localization of proteins

320

321

322

323

324

325

326

327

328

329

330

331

332

333

334

335

336

337

338

339

340

341

342

343

344

345

346

347

348

349

350

351

GO analysis showed that all of the identified proteins in YM18 and ZK001 were involved in 11 subgroups of MF, 19 subgroups of BP, and 14 subgroups of CC (Figure S4). Significant GO enrichment was employed to analyse the DAPs with a corrected FDR $P$-value less than 0.01 and an FC ratio of more than 1.5. Based on GO annotations and enrichments, the DAPs of Group 1 were enriched in molecular function terms for lipid binding (100\%) (Figure 4A) as well as biological process terms for lipid transport (14.06\%), lipid localization (14.06\%), macromolecule localization $(20.31 \%)$, organic substance transport (20.31\%), single-organism transport (15.63\%), and single-organism localization (15.63\%) (Figure 4B). GO classification of Group 2 revealed that the DAPs were enriched in the biological process, cellular component, and molecular function (Figure 4C). No protein was enriched in Group 3 or Group 4. The DAPs of Groups 5 to 10 were also classified into biological process (Figure S5A), cellular component (Figure S5B) and molecular function (Figure S5C). DAPs involved in carbohydrate metabolism and transport, calcium ion binding and protein transport, and fatty acid biosynthesis were further used in cluster analyses.

\section{Accumulation patterns of DAPs and verification of DAPs of interest}

Based on the above analyses, 11 genes which corresponded to DAPs of interest were chosen for qRT-PCR analyses using gene-specific primers (Table S5) to explore the expression profile at the transcription level.

The lodicule morphology showed significant differences between YM18 and ZK001 (Figure 1). We performed qRT-PCR using the RNA of YM18 and ZK001 lodicules to study the transcript profiles of the 11 genes corresponding to the selected DAPs (Figure 5). The results of qRT-PCR indicated that the expression level of the gene A0A1D6CCI3 (encoding the bidirectional sugar transporter SWEET) was expressed in the lodicules at the WAS and GAS of both YM18 and ZK001, with almost no expression at the YAS and AS (Figure 3, Table S7); (Figure 5A). Additionally, the expression level of the gene A0A1D5WGA3 (encoding a nutrient reservoirrelated protein) was extremely down-regulated from the WAS to the GAS in both YM18 and ZK001 (Figure 5B). Though the relative expression level in ZK001 was significantly higher than that in YM18 in the GAS $(P<0.001)$, the relative expression levels were all less than 0.1 in the GAS, YAS or AS in YM18 or ZK001 (Figure 5B). Compared with the relative expression levels of the gene encoding beta-amylase A0A1D5RR02 in YM18, the gene in ZK001 was downregulated during the WAS $(P<0.001)$, GAS $(P<0.05)$, YAS $(P<0.05)$, and AS $(P<0.05)$ (Figure 5C). The relative expression levels of A0A1D5RR02 were all down-regulated from the WAS to

PeerJ reviewing PDF | (2018:12:33913:2:0:NEW 18 Apr 2019) 
352 the YAS in YM18 and ZK001, but there was no significant difference from the YAS to the AS in

353

354

355

356

357

358

359

360

361

362

363

364

365

366

367

368

369

370

371

372

373

374

375

376

377

378

379

380

381

382

383

384

385

386

387

388

389

390

391

YM18 or ZK001 (both $P>0.05$ ) (Figure 5C). Additionally, compared with its expression in the lodicules of YM18, P93594 (beta-amylase)-encoding mRNA was all up-regulated $(P<0.001)$ in the lodicules of ZK001, except that in the YAS (Figure 5D). Interestingly, the mRNA level of sucrose synthase W5B5R3 in ZK001 indicated up-regulation compared with the levels in YM18 at the GAS, YAS, and AS $(P<0.001)$, and down-regulation at the WAS $(P<0.05)$ (Figure 5E). The mRNA levels of A0A1D5SYC3 (a gene encoding cellular glucose homeostasis-related proteins) and A0A1D5VEI9 (a gene encoding cellular glucose homeostasis-related proteins) showed almost the same expression profile as $W 5 B 5 R 3$, except for that of $A 0 A 1 D 5 S Y C 3$ in the WAS and that of A0A1D5VEI9 in the AS (Figures 5E, 5F, and 5G). The relative expression level of A0A1D5RVB4 (a gene encoding cellular glucose homeostasis-related proteins) and $W 5 B 5 R 3$ were similar (Figure $5 \mathrm{E}$ and $5 \mathrm{H}$ ). Compared with expression levels in YM18, the gene expression of beta-glucosidase activity-related protein A0A077S2F2 in ZK001 was down-regulated $(P<0.05)$ during the WAS and GAS and up-regulated $(P<0.001)$ in the AS (Figure 5I).

Calcium ions play a key role in the development of plants. Therefore, the relative expression of the genes encoding calcium ion binding-related protein A0A1D5TN57 and annexin A0A1D5RRV7 were also evaluated to determine the profile during flower development. Compared with levels in YM18, the relative gene expression levels of A0A1D5TN57 in ZK001 were up-regulated during the WAS and YAS(Figure 5K), and those of A0A1D5RRV7 were upregulated during the WAS, YAS and AS (Figure 5J). However, the expression levels of $A 0 A 1 D 5 R R V 7$ and A0A1D5TN57 were all down-regulated $(P<0.05)$ from the WAS to the GAS in ZK001 (Figure 5J and 5K).

\section{Discussion}

\section{Cleistogamy provides structural barriers for diseases of Fusarium head blight}

From the physiological point of view, the flowering stage is regarded as the most susceptible period for primary infection of wheat spikes by FHB because of the opening of wheat florets and the extension of anthers (Pugh, Johann \& Dickson, 1933; Schroeder \& Christensen, 1963; Gilsinger et al., 2005; Schuster \& Ellner, 2008). Barley is a plant that self-fertilizes with permanently closed flowers, but chasmogamous barley varieties are easily infected with Fusarium (Yoshida, Kawada \& Tohnooka, 2005; Culley \& Klooster, 2007). Table 1 shows that the diseased spikelet rate in 2014-2015 was more severe than that in 2013-2014 except in SM3, possibly because of the resistance gene Fhb1 (Rawat et al., 2016). Compared with YM18, which is a wild-type chasmogamous cultivar, the diseased spikelet rate for ZK001, a mutant cleistogamous cultivar, decreased by $38.22 \%$ and $50.00 \%$ in $2013-2014$ and $2014-2015$, respectively (Table 1 ). This indicates that although the diseased spikelet rate is greatly influenced by environmental factors, cleistogamous cultivars that flower partially or completely may have a lower risk of FHB infection than chasmogamous cultivars (Kubo et al., 2010; Wang et al., 2013). Therefore, we further verified the hypothesis that cleistogamous wheat cultivars might have lower Fusarium susceptibility. A practical strategy for controlling FHB would be to introduce the cleistogamous character into other varieties that are suitable for production and promotion but sensitive to FHB through hybridization.

PeerJ reviewing PDF | (2018:12:33913:2:0:NEW 18 Apr 2019) 
392

393

394

395

396

397

398

399

400

401

402

403

404

405

406

407

408

409

410

411

412

413

414

415

416

417

418

419

420

421

422

423

424

425

426

427

428

429

430

431

\section{Lodicules play an important role in glume opening/closing in wheat}

The molecular mechanism for cleistogamy has been intensively studied in rice (Maeng et al., 2006; Yoshida et al., 2007; Ohmori et al., 2012; Ni et al., 2014; Lombardo et al., 2017) and barley (Turuspekov et al., 2004; Hori et al., 2005; Nair et al., 2010; Wang et al., 2013, 2015; Zhang et al., 2016). However, the molecular mechanism for cleistogamy in wheat remains unclear, though it is known that the lodicule is a key factor in glume opening/closing in the monocotyledon. The abnormal lodicules may lack the ability to push the lemma and palea apart during the flowering stage in the cleistogamous mutant ZK001 (Figure 1). This phenomenon is similar to that occurring in barley (Nair et al., 2010).

\section{Carbohydrates and calcium are the main factors regulating lodicule osmotic pressure}

Sucrose is the primary form of sugar transported for photosynthetic carbon assimilation (Chen et al., 2012). The A0A1D6CCI3 gene was expressed in the lodicules of both YM18 and ZK001 (Figure 5A, Table S8). This indicates that carbohydrates can be transferred normally to the lodicules of both YM18 and ZK001. Nevertheless, the starch (Figure 2A, Table S6) and soluble sugar (Figure 2B, Table S6) contents of the YM18 lodicules increased dramatically from the GAS to the YAS. Liu et al. (Liu et al., 2017) suggested that retarded lodicule expansion in ZS97A was caused by reduced water accumulation because of diminished accumulation of osmotic regulation substances. In contrast, the lower soluble sugar content in the lodicules of ZK001 prevented the accumulation of water during the YAS (Figure 2B, Table S6). The lodicule size of YM18 was larger than that of ZK001 because the starch and soluble sugar contents in the lodicules of ZK001 decreased from the GAS to the YAS, leading to little water transfer to the lodicules. The lodicules of wheat swell extensively and subsequently contract after rapid autolysis of the tissues (Craig \& O'Brien, 1975). Accordingly, the starch and soluble sugar contents in the lodicule of YM18 were lower than those in ZKO01 at the AS (Figure 2A and 2B, Table S6).

Cytosolic calcium is an important secondary messenger in plants and plays important roles in the response to both environmental and internal signals (Poovaiah \& Reddy, 1993; Liao, Zheng \& Guo, 2017). Plant annexins are calcium-dependent phospholipid binding proteins with many biological functions; for instance, they participate in calcium ion channel formation, membrane dynamics, plant growth and the stress response (Mortimer et al., 2008; Laohavisit \& Davies, 2011). In this study, the relative gene expression levels of annexin (A0A1D5RRV7) and the calcium ion binding-related protein (A0A1D5TN57) in the lodicules of ZK001 were up-regulated during the WAS compared to those of in the lodicules of YM18 (Figures 5J and 5K). Therefore, we infer that the WAS is a critical period for the lodicules.

\section{An overview of the pathways for proteome metabolic changes in lodicules}

Many substances regulate the osmotic pressure of lodicules, such as soluble sugar (Zee \& O'Brien, 1971; Wang, Gu \& Gao, 1991; Yan et al., 2017), starch (Pissarek, 1971), calcium (Qin, Yang \& Zhao, 2005; Chen et al., 2016) and potassium (Heslop-Harrison \& Heslop-Harrison, 1996; Chen et al., 2016; Liu et al., 2017). Our findings, together with those of previous studies, provide an overview of the metabolic pathways involving the carbohydrates that regulate the osmotic pressure of the lodicules. As shown in Figure 6, sucrose is transferred into the lodicules from the extra- 
432 cellular environment through a bidirectional sugar transporter (A0A1D6CCI3), and is converted 433 into D-fructose-6P by hexokinase (A0A1D5SYC3, A0A1D5RVB4 and A0A1D5VEI9) after being 434 broken down into D-fructose. D-fructose-6P converted to $\alpha$-D-glucose-1P, which can be converted 435 to D-glucose by $\beta$-glucosidase (A0A077S2F2) and synthesised into amylose. The starch formed 436 from amylose can be broken down into D-glucose under the action of $\beta$-amylase (A0A1D5RR02 437 and P93594). UDP-glucose formed from amino sugar and nucleotide sugar can also be converted 438 into D-glucose under the action of $\beta$-glucosidase (A0A077S2F2). The accumulation of D-glucose 439 leads to a change in osmotic pressure in the lodicules. Additionally, $\alpha$-D-glucose-1P can enter the 440

441

442

443

444 445

446

447

448

449

450

451

452

453

454

455

456

457

458

459

460

461

462

463

464

465

466

467

468

469

470

471

472 pentose phosphate pathway and the fatty acid biosynthesis pathway through the formation of $\alpha$-Dglucose-6P and $\beta$-D-glucose-6P. Soluble sugar can also enter and exit cells through the bidirectional sugar transporter. Furthermore, annexin (A0A1D5RRV7) can trigger calcium ion influx, increasing the osmotic pressure. Once the osmotic pressure changes, water accumulates in / is excreted from the cells of the lodicules and induces the expansion / shrinkage of the lodicules.

\section{Conclusions}

The wheat mutant, $Z K 001$, with its atrophied, thin and ineffective lodicules has lost the ability to push the lemma and palea apart in the flower development process. Compared with YM18, ZK001 showed a lower rate of Fusarium infection, presumably because of the cleistogamous phenotype. Furthemore, we speculate that the thin lodicule of ZK001 results from its lower soluble sugar, calcium ion, and potassium ion contents, which are regulated by carbohydrate metabolic, protein transport, and calcium ion binding-related proteins. Though little is known about the mechanism of cleistogamy in wheat, we propose an overview of the metabolic pathway involving the carbohydrate that regulates the osmotic pressure of the lodicules. This study provides foundations for researchers to explore the mechanism of cleistogamy. Furthermore, it shows that it should be possible to generate cleistogamous wheat via conventional crossing, which would improve the FHB resistance of wheat and control the pollen-mediated gene flow of genetically modified wheat.

\section{Acknowledgements}

We thank Prof. Xiue Wang, College of Agriculture, Nanjing Agricultural University, for providing FHB spore F0601. We thank Mr. Shiliang Li and Ms. Shengqun Zheng for field management. We also thank Mrs. Youwei Wu (graphic designer) for instruction in drawing the Figure 6.

\section{References}

Benjamini Y, Hochberg Y. 1995. Controlling the False Discovery Rate - a Practical and Powerful Approach to Multiple Testing. Journal of the Royal Statistical Society Series BMethodological 57:289-300.

Bradford MM. 1976. Rapid and sensitive method for quantitation of microgram quantities of protein utilizing principle of protein-dye binding. Analytical Biochemistry 72:248-254. DOI: 10.1006/abio.1976.9999.

Canovas FM, Dumas-Gaudot E, Recorbet G, Jorrin J, Mock HP, Rossignol M. 2004. Plant proteome analysis. Proteomics 4:285-298. DOI: 10.1002/pmic.200300602. 
473 Chen Y, Ma J, Miller AJ, Luo B, Wang M, Zhu Z, Ouwerkerk PB. 2016. OsCHX14 is Involved

474

475

476

477

478

479

480

481

482

483

484

485

486

487

488

489

490

491

492

493

494

495

496

497

498

499

500

501

502

503

504

505

506

507

508

509

510

511

512

513

514

515

516

517

518 in the $\mathrm{K}^{+}$Homeostasis in Rice (Oryza sativa) Flowers. Plant Cell Physiol 57:1530-1543. DOI: $10.1093 / \mathrm{pcp} / \mathrm{pcw} 088$.

Chen LQ, Qu XQ, Hou BH, Sosso D, Osorio S, Fernie AR, Frommer WB. 2012. Sucrose Efflux Mediated by SWEET Proteins as a Key Step for Phloem Transport. Science 335:207-211. DOI: $10.1126 /$ science. 1213351.

Craig S, O'Brien TP. 1975. The Lodicules of Wheat: Pre- and Post-Anthesis. Australian Journal of Botany 23:451-458. DOI: 10.1071/BT9750451.

Culley TM, Klooster MR. 2007. The cleistogamous breeding system: A review of its frequency, evolution, and ecology in angiosperms. Botanical Review 73:1. DOI: 10.1663/00068101(2007)73[1:TCBSAR]2.0.CO;2.

Diallo AO, Agharbaoui Z, Badawi MA, Ali-Benali MA, Moheb A, Houde M, Sarhan F. 2014. Transcriptome analysis of an $m v p$ mutant reveals important changes in global gene expression and a role for methyl jasmonate in vernalization and flowering in wheat. $J$ Exp Bot 65:2271-2286. DOI: 10.1093/jxb/eru102.

Elias JE, Gygi SP. 2007. Target-decoy search strategy for increased confidence in large-scale protein identifications by mass spectrometry. Nat Methods 4:207-214. DOI: $10.1038 /$ nmeth 1019.

FAO. 2015. FAO statistical pocketbook, World food and agriculture 2015, Rome, Food and Agricultural Organization of the United Nations.

Feng YL, Wang KT, Ma C, Zhao YY, Yin J. 2015. Virus-induced gene silencing-based functional verification of six genes associated with vernalization in wheat. Biochem Biophys Res Commun 458:928-933. DOI: 10.1016/j.bbrc.2015.02.064.

Gilsinger J, Kong L, Shen X, Ohm H. 2005. DNA markers associated with low Fusarium head blight incidence and narrow flower opening in wheat. Theoretical and Applied Genetics 110:1218-1225. DOI: 10.1007/s00122-005-1953-4.

Guo Z, Schnurbusch T. 2015. Variation of floret fertility in hexaploid wheat revealed by tiller removal. J Exp Bot 66:5945-5958. DOI: 10.1093/jxb/erv303.

Heslop-Harrison Y, Heslop-Harrison JS. 1996. Lodicule Function and Filament Extension in the Grasses: Potassium Ion Movement and Tissue Specialization. Annals of Botany 77:573582. DOI: 10.1006/anbo.1996.0072.

Hollingsworth CR, Motteberg CD, Wiersma J V, Atkinson LM. 2008. Agronomic and Economic Responses of Spring Wheat to Management of Fusarium Head Blight. Plant Disease 92:1339-1348. DOI: 10.1094/PD1S-92-9-1339.

Hori K, Kobayashi T, Sato K, Takeda K. 2005. QTL analysis of Fusarium head blight resistance using a high-density linkage map in barley. Theor Appl Genet 111:1661-1672. DOI: 10.1007/s00122-005-0102-4.

Kang DH, Gho YS, Suh MK, Kang CH. 2002. Highly sensitive and fast protein detection with coomassie brilliant blue in sodium dodecyl sulfate-polyacrylamide gel electrophoresis. Bulletin of the Korean Chemical Society 23:1511-1512. DOI: 10.5012/bkcs.2002.23.11.1511.

Kirby EJM, Appleyard M. 1987. Cereal Development Guide. 2nd ed Stoneleigh, UK: NAC Cereal Unit, 85pp.

Kubo K, Kawada N, Fujita M, Hatta K, Oda S, Nakajima T. 2010. Effect of cleistogamy on Fusarium head blight resistance in wheat. Breed Sci 60:405-411. DOI: $10.1270 /$ jsbbs.60.405. 
519 Kumar RR, Goswami S, Sharma SK, Kala YK, Rai GK, Mishra DC, Grover M, Singh GP, 520 Pathak H, Rai A, Chinnusamy V, Rai RD. 2015. Harnessing Next Generation Sequencing in

521

522

523

524

525

526

527

528

529

530

531

532

533

534

535

536

537

538

539

540

541

542

543

544

545

546

547

548

549

550

551

552

553

554

555

556

557

558

559

560

561

562

563

564 Climate Change: RNA-Seq Analysis of Heat Stress-Responsive Genes in Wheat (Triticum aestivum L.). OMICS 19:632-647. DOI: 10.1089/omi.2015.0097.

Laohavisit A, Davies JM. 2011. Annexins. New Phytologist 189:40-53. DOI: 10.1111/j.14698137.2010.03533.x.

Li QY, Qin Z, Jiang YM, Shen CC, Duan ZB, Niu JS. 2014. Screening wheat genotypes for resistance to black point and the effects of diseased kernels on seed germination. Journal of Plant Diseases \& Protection 121:79-88. DOI: 10.1007/BF03356495.

Liao C, Zheng Y, Guo Y. 2017. MYB30 transcription factor regulates oxidative and heat stress responses through ANNEXIN - mediated cytosolic calcium signaling in Arabidopsis. New Phytologist 216:163. DOI: 10.1111/nph.14679.

Liu L, Zou ZS, Qian K, Xia C, He Y, Zeng HL, Zhou X, Riemann M, Yin CX. 2017. Jasmonic acid deficiency leads to scattered floret opening time in cytoplasmic male sterile rice Zhenshan 97A. Journal of Experimental Botany 68:4613-4625. DOI: 10.1093/jxb/erx251.

Livak KJ, Schmittgen TD. 2001. Analysis of relative gene expression data using real-time quantitative PCR and the $2^{-\Delta \Delta \mathrm{CT}}$ Method. Methods 25:402-408. DOI:

10.1006/meth.2001.1262.

Lombardo F, Kuroki M, Yao SG, Shimizu H, Ikegaya T, Kimizu M, Ohmori S, Akiyama T, Hayashi T, Yamaguchi T, Koike S, Yatou O, Yoshida H. 2017. The superwoman 1cleistogamy 2 mutant is a novel resource for gene containment in rice. Plant Biotechnology Journal 15:97-106. DOI: 10.1111/pbi.12594.

Ma J, Li R, Wang H, Li D, Wang X, Zhang Y, Zhen W, Duan H, Yan G, Li Y. 2017. Transcriptomics Analyses Reveal Wheat Responses to Drought Stress during Reproductive Stages under Field Conditions. Front Plant Sci 8:592. DOI: 10.3389/fpls.2017.00592.

Maeng JY, Won YJ, Piao R, Cho YI, Jiang W, Chin JH, Koh HJ. 2006. Molecular mapping of a gene "ld(t)" controlling cleistogamy in rice. Theoretical and Applied Genetics 112:14291433. DOI: $10.1007 / \mathrm{s} 00122-006-0244-\mathrm{z}$.

Mortimer JC, Laohavisit A, Macpherson N, Webb A, Brownlee C, Battey NH, Davies JM. 2008. Annexins: multifunctional components of growth and adaptation. Journal of Experimental Botany 59:533. DOI: 10.1093/jxb/erm344.

Muqaddasi QH, Brassac J, Borner A, Pillen K, Roder MS. 2017. Genetic Architecture of Anther Extrusion in Spring and Winter Wheat. Front. Plant Sci 8:754. DOI: 10.3389/fpls.2017.00754.

Nair SK, Wang N, Turuspekov Y, Pourkheirandish M, Sinsuwongwat S, Chen G, Sameri M, Tagiri A, Honda I, Watanabe Y, Kanamori H, Wicker T, Stein N, Nagamura Y, Matsumoto T, Komatsuda T. 2010. Cleistogamous flowering in barley arises from the suppression of microRNA-guided HvAP2 mRNA cleavage. Proceedings of the National Academy of Sciences of the United States of America 107:490-495. DOI: 10.1073/pnas.0909097107.

Ni DH, Li J, Duan YB, Yang YC, Wei PC, Xu RF, Li CR, Liang DD, Li H, Song FS, Ni JL, Li L, Yang JB. 2014. Identification and utilization of cleistogamy gene $c l 7(t)$ in rice (Oryza sativa L.). J Exp Bot 65:2107-2117. DOI: 10.1093/jxb/eru074.

Ning S, Wang N, Sakuma S, Pourkheirandish M, Wu J, Matsumoto T, Koba T, Komatsuda T. 2013. Structure, transcription and post-transcriptional regulation of the bread wheat orthologs of the barley cleistogamy gene Cly1. Theoretical and Applied Genetics 126:12731283. DOI: 10.1007/s00122-013-2052-6. 
565 Ohmori S, Tabuchi H, Yatou O, Yoshida H. 2012. Agronomic traits and gene containment

566

567

568

569

570

571

572

573

574

575

576

577

578

579

580

581

582

583

584

585

586

587

588

589

590

591

592

593

594

595

596

597

598

599

600

601

602

603

604

605

606

607

608

609 capability of cleistogamous rice lines with the superwoman1-cleistogamy mutation. Breed Sci 62:124-132. DOI: 10.1270/jsbbs.62.124.

PARRY DW, JENKINSON P, McLEOD L. 1995. Fusarium ear blight (scab) in small grain cereals-a review. Plant Pathology 44:207-238. DOI: doi:10.1111/j.13653059.1995.tb02773.x.

Pissarek HP. 1971. Untersuchungen über Bau und Funktion der Gramineen-Lodiculae. Beitrage Zur Biologie Der Pflanzen 47:313-370.

Poovaiah BW, Reddy ASN. 1993. Calcium and Signal-Transduction in Plants. Critical Reviews in Plant Sciences 12:185-211. DOI: Doi 10.1080/713608046.

Pugh GW, Johann H, Dickson JG. 1933. Factors affecting infection of Wheat heads by Gibberella saubiuetii. J Agric Res 46:771-797.

Qin Y, Yang J, Zhao J. 2005. Calcium changes and the response to methyl jasmonate in rice lodicules during anthesis. Protoplasma 225:103-112. DOI: 10.1007/s00709-005-0086-6.

Rawat N, Pumphrey MO, Liu S, Zhang X, Tiwari VK, Ando K, Trick HN, Bockus WW, Akhunov E, Anderson JA, Gill BS. 2016. Wheat Fhb1 encodes a chimeric lectin with agglutinin domains and a pore-forming toxin-like domain conferring resistance to Fusarium head blight. Nat Genet 48:1576-1580. DOI: 10.1038/ng.3706.

Sage GCM, De Isturiz MJ. 1974. The inheritance of anther extrusion in two spring wheat varieties. Theoretical and Applied Genetics 45:126-133. DOI: 10.1007/bf00291142.

Schägger H. 2006. Tricine-SDS-PAGE. Nature Protocols 1:16-22. DOI: 10.1038/nprot.2006.4.

Scheltema RA, Hauschild JP, Lange O, Hornburg D, Denisov E, Damoc E, Kuehn A, Makarov A, Mann M. 2014. The Q Exactive HF, a Benchtop Mass Spectrometer with a Pre-filter, High-performance Quadrupole and an Ultra-high-field Orbitrap Analyzer. Molecular \& Cellular Proteomics 13:3698-3708. DOI: 10.1074/mcp.M114.043489.

Schroeder HW, Christensen JJ. 1963. Factors affecting resistance of Wheat to scab caused by Gibberella zeae. Phytopathology 53:831.

Schuster R, Ellner FM. 2008. Level of Fusarium infection in wheat spikelets related to location and number of inoculated spores. Mycotoxin Research 24:80-87. DOI: 10.1007/BF02985285.

Schweppe RE, Haydon CE, Lewis TS, Resing KA, Ahn NG. 2003. The characterization of protein post-translational modifications by mass spectrometry. Acc Chem Res 36:453-461. DOI: $10.1021 / \operatorname{ar} 0201431$.

Sharma M, Gupta SK, Majumder B, Maurya VK, Deeba F, Alam A, Pandey V. 2017. Salicylic acid mediated growth, physiological and proteomic responses in two wheat varieties under drought stress. J Proteomics 163:28-51. DOI: 10.1016/j.jprot.2017.05.011.

Turuspekov Y, Mano Y, Honda I, Kawada N, Watanabe Y, Komatsuda T. 2004. Identification and mapping of cleistogamy genes in barley. Theoretical and Applied Genetics 109:480487. DOI: $10.1007 / \mathrm{s} 00122-004-1673-1$.

Untergasser A, Cutcutache I, Koressaar T, Ye J, Faircloth BC, Remm M, Rozen SG. 2012. Primer3--new capabilities and interfaces. Nucleic Acids Research 40:e115. DOI: 10.1093/nar/gks596.

Unwin RD, Griffiths JR, Whetton AD. 2010. Simultaneous analysis of relative protein expression levels across multiple samples using iTRAQ isobaric tags with 2D nano LCMS/MS. Nature Protocols 5:1574-1582. DOI: 10.1038/nprot.2010.123. 
610 Vizcaino JA, Csordas A, del-Toro N, Dianes JA, Griss J, Lavidas I, Mayer G, Perez-Riverol Y, 611 Reisinger F, Ternent T, Xu QW, Wang R, Hermjakob H. 2016. 2016 update of the PRIDE

612

613

614

615

616

617

618

619

620

621

622

623

624

625

626

627

628

629

630

631

632

633

634

635

636

637

638

639

640

641

642

643

644

645

646

647

648

649

650

651

652

653 database and its related tools. Nucleic Acids Research 44:D447-D456. DOI: 10.1093/nar/gkv1145.

Walter S, Nicholson P, Doohan FM. 2010. Action and reaction of host and pathogen during Fusarium head blight disease. New Phytol 185:54-66. DOI: 10.1111/j.14698137.2009.03041.X.

Wang Z, Gu Y, Gao Y. 1991. Studies on the mechanism of the anthesis of rice III. structure of the lodicule and changes of its contents during flowering. Acta Agronomica Sinica 17:96101.

Wang N, Ning S, Pourkheirandish M, Honda I, Komatsuda T. 2013. An alternative mechanism for cleistogamy in barley. Theoretical and Applied Genetics 126:2753-2762. DOI: 10.1007/s00122-013-2169-7.

Wang N, Ning S, Wu J, Tagiri A, Komatsuda T. 2015. An epiallele at clyl affects the expression of floret closing (cleistogamy) in barley. Genetics 199:95-104. DOI: 10.1534/genetics.114.171652.

Winfield MO, Lu C, Wilson ID, Coghill JA, Edwards KJ. 2010. Plant responses to cold: Transcriptome analysis of wheat. Plant Biotechnol J 8:749-771. DOI: $10.1111 / \mathrm{j} .1467-$ 7652.2010.00536.x.

Won YJ, Koh HJ. 1998. Inheritance of cleistogamy and its interrelationship between other agronomic characters in rice. Korean Journal of Breeding.

Wu WW, Wang GH, Baek SJ, Shen RF. 2006. Comparative study of three proteomic quantitative methods, DIGE, cICAT, and iTRAQ, using 2D gel- or LC-MALDI TOF/TOF. Journal of Proteome Research 5:651-658. DOI: 10.1021/pr050405o.

Yan S, Tang Z, Su W, Sun W. 2005. Proteomic analysis of salt stress-responsive proteins in rice root. Proteomics 5:235-244. DOI: 10.1002/pmic.200400853.

Yan H, Zhang B, Zhang Y, Chen X, Xiong H, Matsui T, Tian X. 2017. High Temperature Induced Glume Closure Resulted in Lower Fertility in Hybrid Rice Seed Production. Front Plant Sci 7:1960. DOI: 10.3389/fpls.2016.01960.

Yang Z, Guo GY, Zhang MY, Liu CY, Hu Q, Lam H, Cheng H, Xue Y, Li JY, Li N. 2013. Stable Isotope Metabolic Labeling-based Quantitative Phosphoproteomic Analysis of Arabidopsis Mutants Reveals Ethylene-regulated Time-dependent Phosphoproteins and Putative Substrates of Constitutive Triple Response 1 Kinase. Molecular \& Cellular Proteomics 12:3559-3582. DOI: 10.1074/mcp.M113.031633.

Yang Z, Peng Z, Wei S, Liao M, Yu Y, Jang Z. 2015. Pistillody mutant reveals key insights into stamen and pistil development in wheat (Triticum aestivum L.). BMC Genomics 16:211. DOI: $10.1186 / \mathrm{s} 12864-015-1453-0$.

Yoshida H, Itoh J, Ohmori S, Miyoshi K, Horigome A, Uchida E, Kimizu M, Matsumura Y, Kusaba M, Satoh H, Nagato Y. 2007. superwoman1-cleistogamy, a hopeful allele for gene containment in GM rice. Plant Biotechnol J 5:835-846. DOI: 10.1111/j.14677652.2007.00291.x.

Yoshida M, Kawada N, Tohnooka T. 2005. Effect of row type, flowering type and several other spike characters on resistance to Fusarium head blight in barley. Euphytica 141:217-227. DOI: $10.1007 / \mathrm{s} 10681-005-7008-8$. 
654

655

656

657

658

659

660

661

662

663

664

665

666

667

668

669

670

671

672

673

674

675

676

677

678
Yu SQ, Ma ZH, Zhang M, Peng H, Chai CL, Cui YJ. 2019. Occurring characteristics of wheat scab and its integrated controlling techniques in Henan province. China plant protection 39:53-60. (Chinese)

Yumurtaci A, Sipahi H, Al-Abdallat A, Jighly A, Baum M. 2017. Construction of new ESTSSRs for Fusarium resistant wheat breeding. Comput Biol Chem 68:22-28. DOI: 10.1016/j.compbiolchem.2017.02.003.

Zadoks JC, Chang TT, Konzak CF. 1974. A decimal code for the growth stages of cereals. Weed Research 14:415-421.

Zange BJ, Kang Z, Buchenauer H. 2005. Effect of Folicur ${ }^{\circledR}$ on infection process of Fusarium culmorum in wheat spikes / Wirkung von Folicur ${ }^{\circledR}$ auf den Infektionsprozess von Fusarium culmorum in Weizenähren. Zeitschrift Für Pflanzenkrankheiten Und Pflanzenschutz 112:52-64.

Zee S, O'Brien T. 1971. The Vascular Tissue of the Lodicules of Wheat. Australian Journal of Biological Sciences 24:797-804.

Zhang X, Guo B, Lan G, Li H, Lin S, Ma J, Lv C, Xu R. 2016. A Major QTL, Which Is Colocated with clyl, and Two Minor QTLs Are Associated with Glume Opening Angle in Barley (Hordeum vulgare L.). Front. Plant Sci 7:1585. DOI: 10.3389/fpls.2016.01585.

Zhang H, Han B, Wang T, Chen S, Li H, Zhang Y, Dai S. 2012. Mechanisms of plant salt response: insights from proteomics. J Proteome Res 11:49-67. DOI: 10.1021/pr200861w.

Zhao Q, Zhang H, Wang T, Chen S, Dai S. 2013. Proteomics-based investigation of saltresponsive mechanisms in plant roots. J Proteomics 82:230-253. DOI: 10.1016/j.jprot.2013.01.024. 


\section{Figure 1}

Characteristics of genotypes in the 2 differential individual lines of YM18 and ZK001.

Comparison of the inflorescence details between YM18 and ZKO01 in post-anthesis stage (Bar $=1 \mathrm{~cm})(\mathbf{A})$. Lodicules of YM18 (B) and ZK001 (C) which were sampled in GAS and cultured on MS media containing graphite were observed after 90 minutes by microscope (Bar $=1$ mm). (D) Comparison of lodicule width between YM18 (white column) and ZK001 (gray column). The results presented are the means of four independent experiments expressed as the mean \pm standard error of the mean (SEM). The data were further analyzed using an ANOVA at a 95\% confidence level following Duncan's test (SPSS 18.0, IBM, Somers, NY, USA). The level of significance was set at $P \leq 0.05$ or $P \leq 0.001$.

A

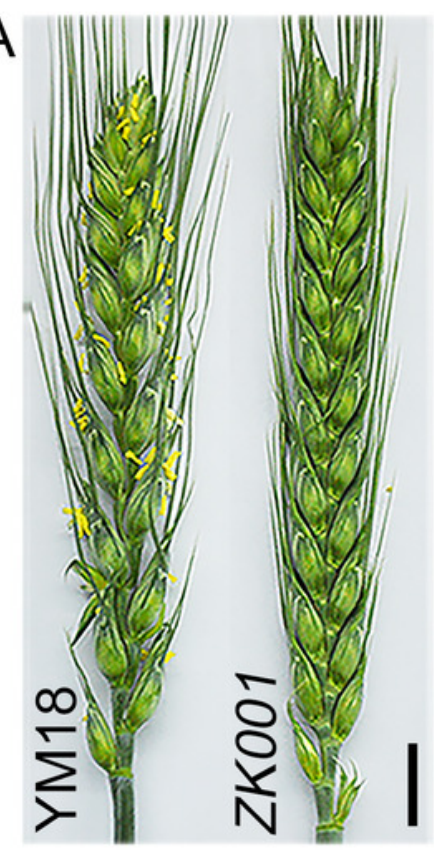

B

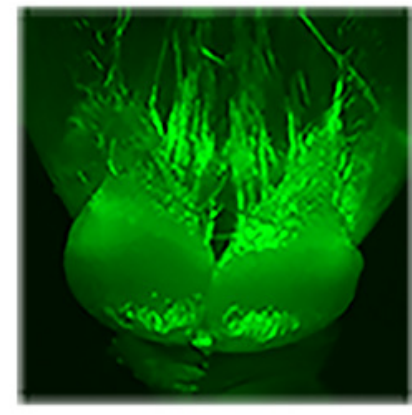

C

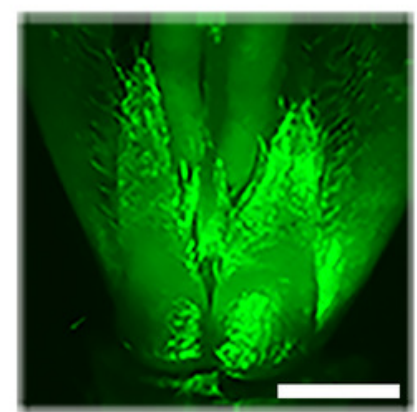

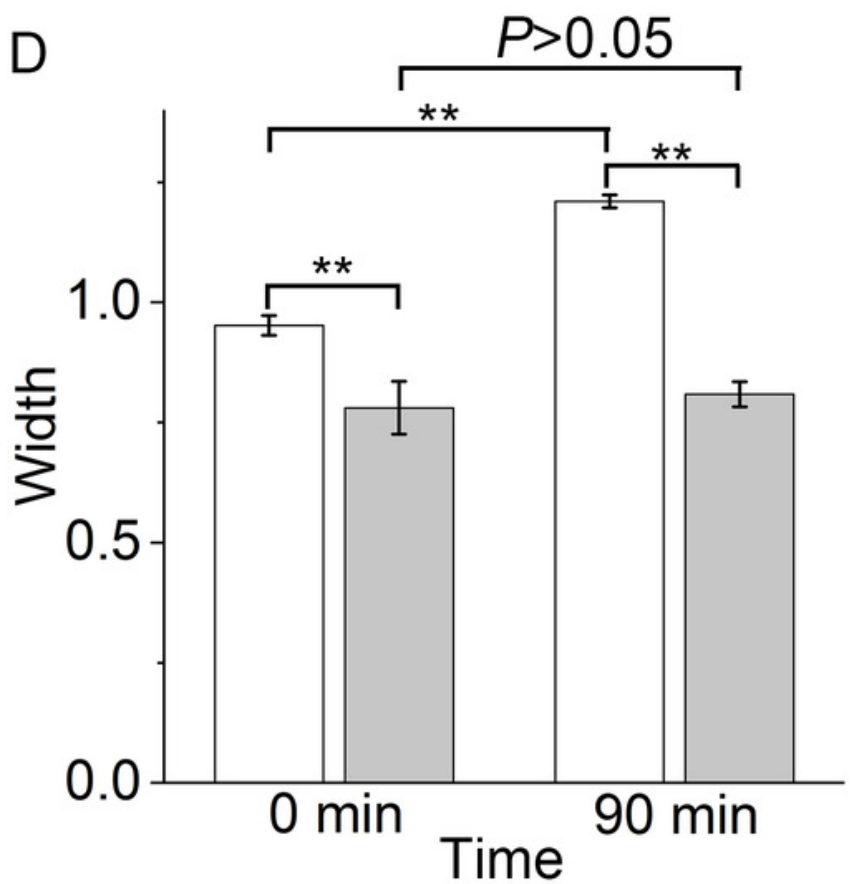




\section{Figure 2}

Starch, soluble sugar content in lodicules of YM18 (gray column) and ZK001 (black column).

A: comparison of starch content change tendency in lodicules between YM18 and ZK001. B: comparison of soluble sugar content change tendency in lodicules between YM18 and ZK001. $\mathrm{PL}^{1}$ : pair of lodicules (PL). The results presented are the means of three independent experiments. Error bars, s.d. Columns marked with different lowercase letter indicate difference in means using the one-way ANOVA LSD analysis of PASW Statistics software among four flower development stage of YM18 (gray lowercase) and ZK001 (black lowercase). The asterisk indicates the difference between YM18 and ZK001 at WAS, GAS, YAS and AS, respectively. The data were further analyzed using an ANOVA at a 95\% confidence level following Duncan's test (SPSS 18.0, IBM, Somers, NY, USA). The level of significance was set at $P \leq 0.05$ or $P \leq 0.001$.

A

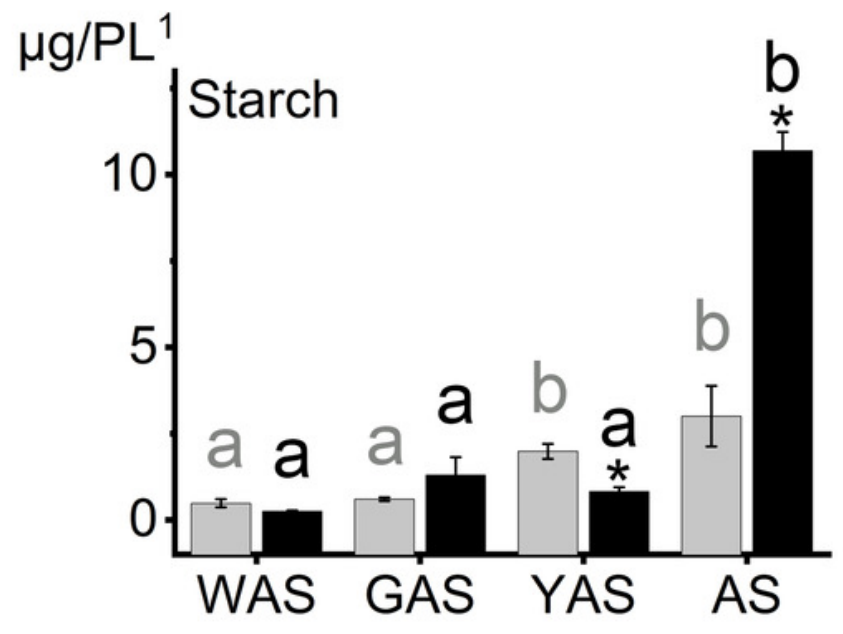

B

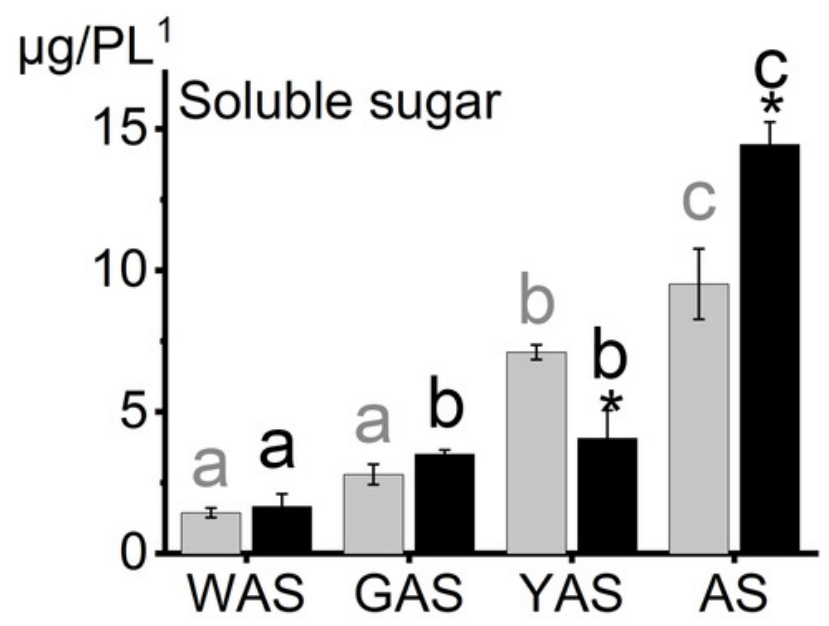




\section{Figure 3}

Assessment of iTRAQ analysis for peptides identification and quantitation.

A: The distribution of the identification peptide segments counts corresponding to the identification of proteins number. B: Distribution of protein's molecular weight. C:

Quantification of peptide-length coverage in the identified proteins. D: Coverage of protein mass distribution.

A

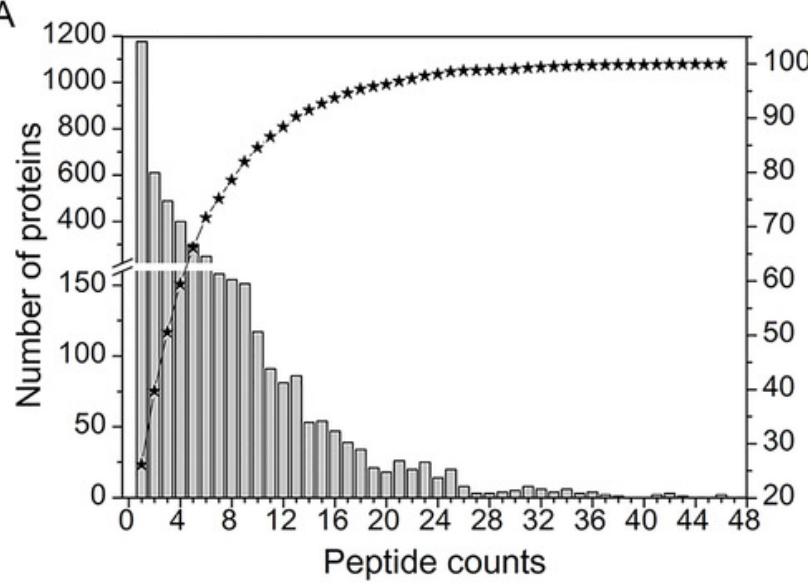

C

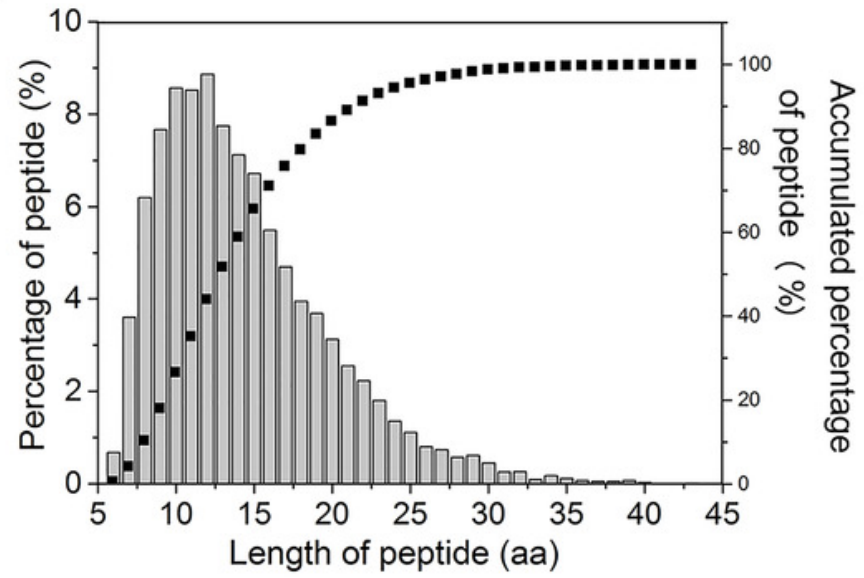

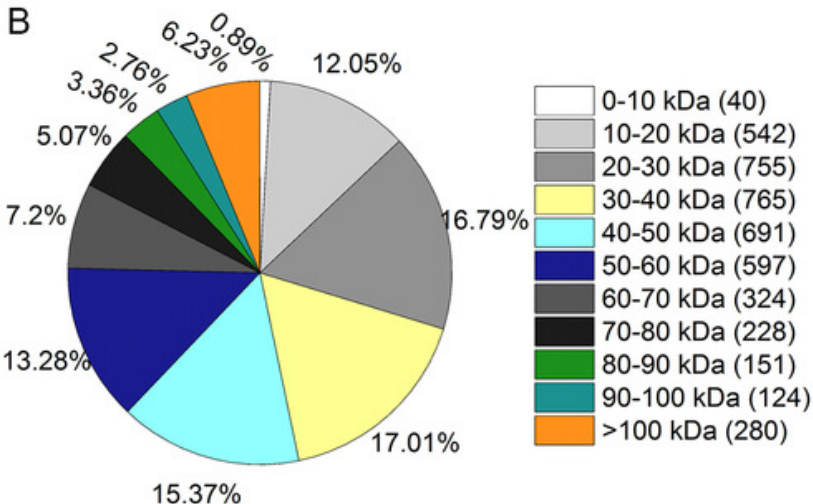

Distribution of protein's molecular weight

$\mathrm{D}$

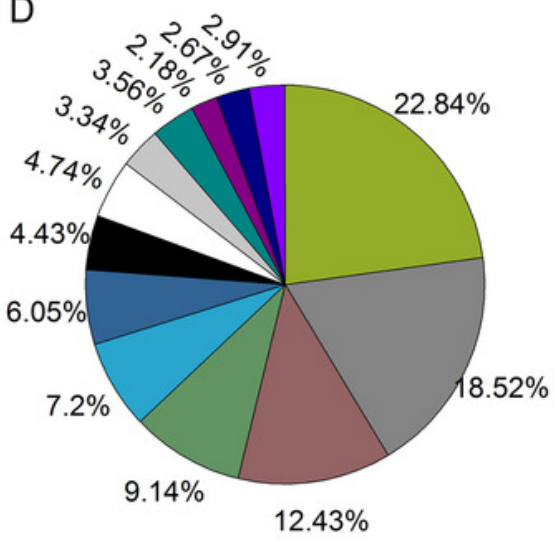

$0-5 \%(1027)$ $5-10 \%(833)$ $10-15 \%(559)$ $15-20 \%(411)$ $20-25 \%(324)$ $25-30 \%(272)$ $30-35 \%(199)$ $35-40 \%(213)$ $40-45 \%(150)$ $45-50 \%(160)$ $50-55 \%(98)$ $55-60 \%(120)$ $60-100 \%(131)$

Distribution of protein's sequences coverage 
Figure 4

GO classification of DAPs of Group 1 to 4 from four flower development stages in YM18 and ZKOOI based on GO enrichment.

A: molecular function of Group 1; B: biological process of Group 1; C: biological process, cellular component and molecular function of Group 2. No protein was enriched in Group 3 or Group 4 basing on GO enrichment. $(0.667<\mathrm{FC}<1.5$, corrected $P$-value $<0.01$, PSMs $\geq 2)$. 

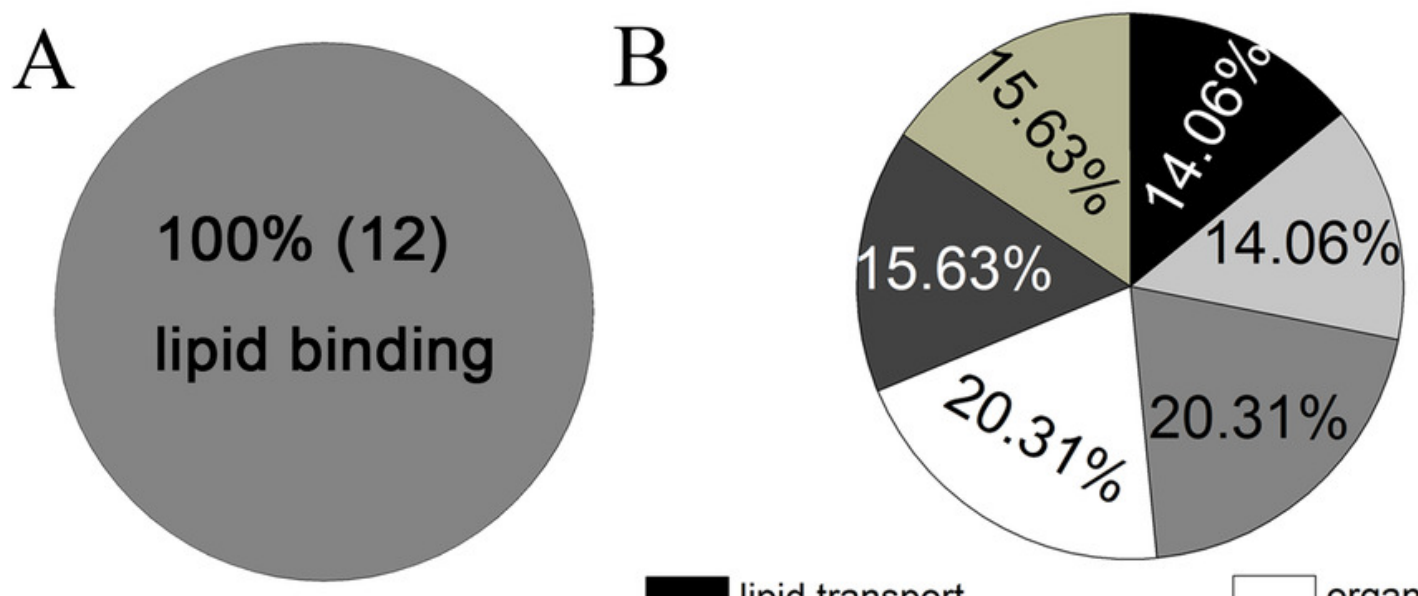

C

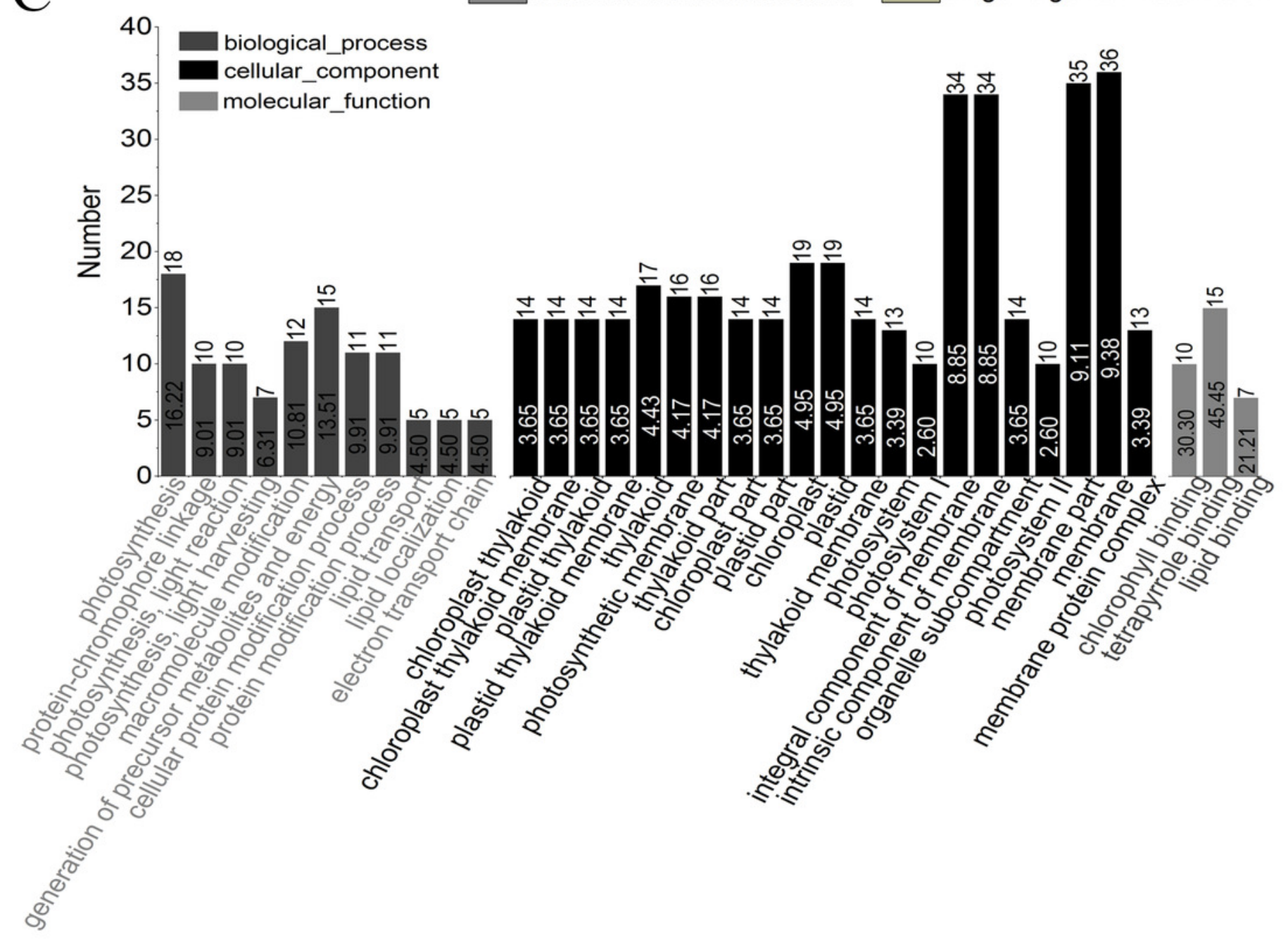

lipid transport lipid localization macromolecule localization organic substance transport single-organism transport single-organism localization 


\section{Figure 5}

Relative expression profile of related genes which corresponded to DAPs in lodicules of YM18 (gray column) and ZKOO1 (black column).

A to I: relative expression profile of carbohydrate-related genes in lodicules of YM18 and ZK001. J to K: relative expression profile of calcium ion binding-related genes in lodicules of YM18 and ZK001. The results presented are the means of three independent experiments. Error bars, s.d. Columns marked with different lowercase letter indicate difference in means of YM18 (gray lowercase) and ZK001 (black lowercase) using the one-way ANOVA LSD analysis of PASW Statistics software. The asterisk indicates the difference between YM18 and ZK001 at WAS, GAS, YAS and AS, respectively. The data were further analyzed using an ANOVA at a 95\% confidence level following Duncan's test (SPSS 18.0, IBM, Somers, NY, USA). The level of significance was set at $P \leq 0.05$ or $P \leq 0.001$.
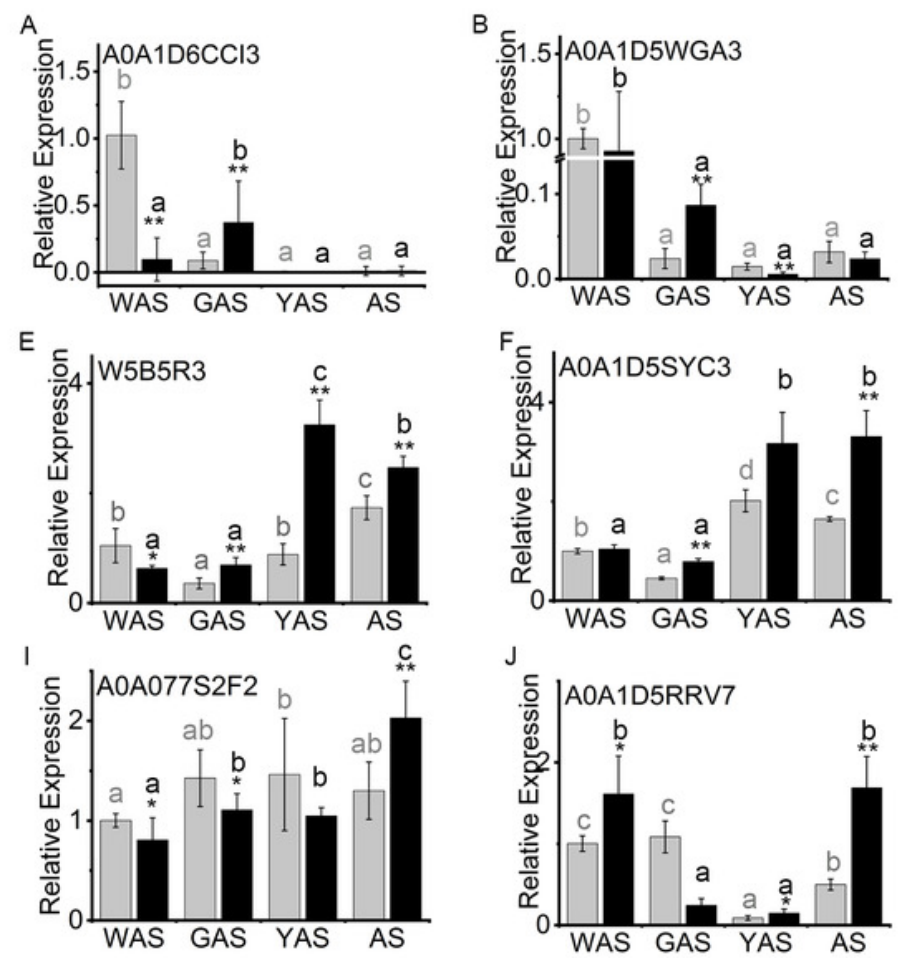

C
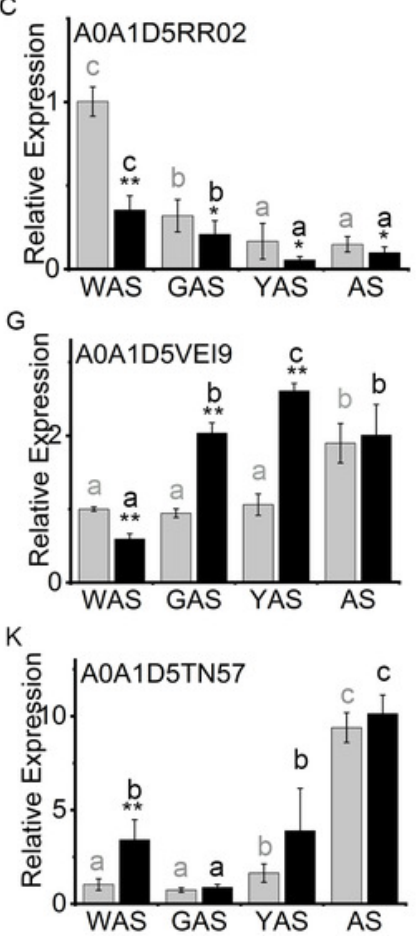
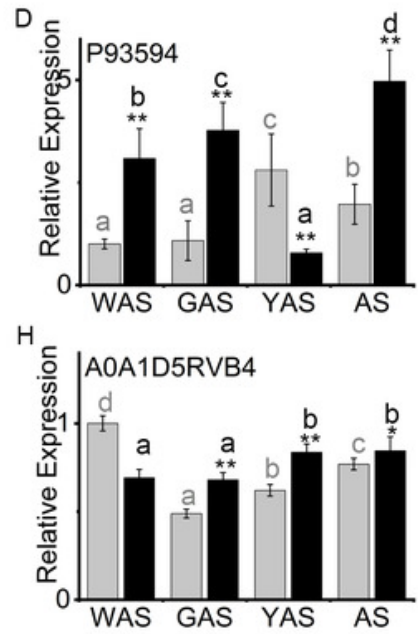


\section{Figure 6}

An overview of the pathway for proteome metabolic changes between YM18 and ZK001.

A: A0A1D6CCI3 (bidirectional sugar transporter SWEET); B: A0A1D5SYC3 (cellular glucose homeostasis-related proteins); C: A0A1D5RVB4 (cellular glucose homeostasis-related proteins); D: A0A1D5VEI9 (cellular glucose homeostasis-related proteins); E: A0A077S2F2 (beta-glucosidase activity-related protein); F: W5B5R3 (sucrose synthase); G: A0A1D5RR02 (beta-amylase); H: A0A1D5RRV7 (annexin); I: A0A1D5TN57 (calcium ion binding-related protein); J: A0A1D5WGA3 (nutrient reservoir-related protein); K: P93594 (beta-amylase).

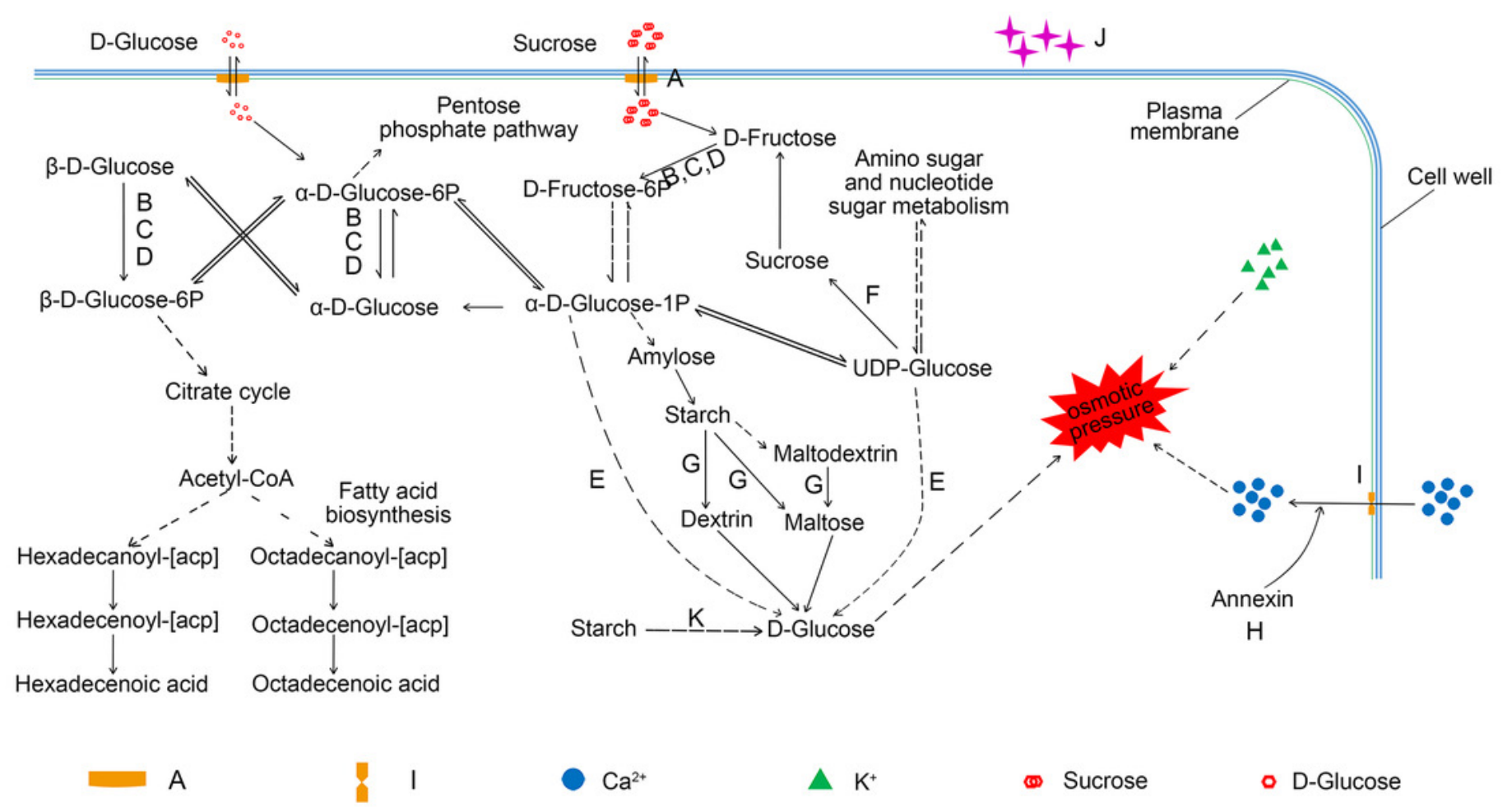




\section{Table 1 (on next page)}

Comparison of diseased spikelets rate by Fusarium head blight in 2013-2014 and 2014-2015 in four varieties. 
1 Table 1. Comparison of diseased spikelets rate by Fusarium head blight in 2013-2014 and 2014-2015 in four 2 varieties.

\begin{tabular}{ccc}
\hline \multirow{2}{*}{ Variety } & \multicolumn{2}{c}{ Diseased spikelets rate ${ }^{\mathrm{a}}(\%)$} \\
& $2013-2014$ & $2014-2015$ \\
\hline SM3 & $7.03 \pm 2.23$ & $8.61 \pm 3.40$ \\
ZK001 & $9.39 \pm 3.31$ & $17.60 \pm 3.60$ \\
YM18 & $15.20 \pm 2.46$ & $35.16 \pm 3.71$ \\
AK58 & $20.41 \pm 6.76$ & $38.12 \pm 6.13$
\end{tabular}

3 a: Diseased spikelets rate $=$ the number of infected spikelets/total number of spikelets $\times 100 \%$. The results presented 4 are the means of three independent experiments. Error bars, s.d.

5 


\section{Table 2 (on next page)}

The number of differentially abundant proteins (DAPs) at four flower development stages.

$(0.667<$ FC $<1.5$, corrected $P$-value $<0.01)$ 
1 Table 2. The number of differentially abundant proteins (DAPs) at four flower development stages. $(0.667<$ FC $<$

21.5 , corrected $P$-value $<0.01$, PSMs $\geqslant 2$ )

\begin{tabular}{|c|c|c|c|c|}
\hline \multirow{2}{*}{ Groups } & \multirow{2}{*}{ Total } & \multicolumn{3}{|c|}{ Corrected $P$-value $<0.01$} \\
\hline & & Increasing-DAPs & $\begin{array}{c}\text { Decreasing- } \\
\text { DAPs }\end{array}$ & Total DAPs \\
\hline Group 1 & 4188 & 7 & 9 & 16 \\
\hline Group 2 & 4188 & 9 & 38 & 47 \\
\hline Group 3 & 4189 & 1 & 1 & 2 \\
\hline Group 4 & 4189 & 0 & 0 & 0 \\
\hline Group 5 & 4188 & 0 & 11 & 11 \\
\hline Group 6 & 4188 & 27 & 97 & 124 \\
\hline Group 7 & 4188 & 31 & 74 & 105 \\
\hline Group 8 & 4188 & 4 & 11 & 15 \\
\hline Group 9 & 4188 & 123 & 175 & 298 \\
\hline Group 10 & 4188 & 94 & 94 & 188 \\
\hline
\end{tabular}

3 Note: Group 1: ZK001-WAS vs YM18-WAS, Group 2: ZK001-GAS vs YM18-GAS, Group 3:

4 ZK001-YAS vs YM18-YAS, Group 4: ZK001-AS vs YM18-AS, Group 5: YM18-WAS vs YM18-

5 GAS, Group 6: YM18-WAS vs YM18-YAS, Group 7: YM18-WAS vs YM18-AS, Group 8:

$6 \quad Z K 001$-WAS vs ZK001-GAS, Group 9: ZK001-WAS vs ZK001-YAS, and Group 10: ZK001-WAS

7 vs ZK001-AS. 